\title{
Lexical Analysis of Political Texts on International Relations
}

\author{
Sevil Huseynova ${ }^{1}$ \\ ${ }^{1}$ Department of Linguoculturology, Azerbaijan University of Languages, Azerbaijan \\ Correspondence: Sevil Huseynova, Department of Linguoculturology, Azerbaijan University of Languages, \\ Azerbaijan. E-mail: Seville.huseynova@gmail.com
}

\author{
Received: May 15, 2015 Accepted: April 10, 2015 Online Published: May 30, 2015 \\ doi:10.5539/ijel.v5n3p148 URL: http://dx.doi.org/10.5539/ijel.v5n3p148
}

\begin{abstract}
Currently, according to the increased interest in the processes taking place in the international arena, a comprehensive study of the problem of texts on international relations is of particular importance. It would be wrong to say that these types of texts have not previously been investigated. First of all, they were the subject of research translators. For the absence of special linguistic research object of political texts on international relations, the relevance of the work has not been determined. The problem of political texts on international relations as functional-stylistic variety of political language and language for specific purposes has not still been the subject of a separate study up to now.

In this research, the written form of the language of political texts on international relations, its language features as "language for specific purposes" are investigated at the lexical level. Here features and patterns of functioning of lexical units are defined, original, standard and frequently used general-political and special-political last syntagmatic sequences are distinguished. In this research main attempts have been made to discover register peculiarities of political texts on international relations at the lexical level which can be considered scientific innovation. Here, they are analyzed as a functional whole unitcombined with the general field of activity. Trying to coordinate the didactic learning objectives with the results of the linguistic analysis of a particular speech register contributes to the practice of teaching language for specific purposes. The theoretical significance of the study is that in the work we develop a theory of functional styles, some aspects of learning the marginal syntagmatic units are worked out, all of these that lay the foundation for further study of phraseology.
\end{abstract}

Keywords: political text on international relations, the marginal syntagmatic sequences

\section{Introduction}

Investigations in the field of functional stylistics are still actively developing the branch of linguistics, which are widely demanded in the practice of teaching foreign languages. Although scientists were engaged in the analysis of scientific and technical terms in the 1930s, the most intense issue of functional styles began to develop only in the $60-80 \mathrm{~s}$, when there was a need to develop the theory and practice of learning and teaching thematically unified linguistic resources corresponding to specific human communication, due to certain extra-linguistic reasons; such as the weakening of international tension, scientific and technical progress and the expansion of scientific relations.

Thesis on the functional variability of linguistic forms recognized by philologists unanimously: "Language varies as its function varies; it differs in different situations. The name given to a variety of a language is distinguished according to use is register" (Close, 187). "The idea of the existence of a special register of political speech expressed long before the formation of functional stylistics as a special philological discipline". However, the question of the division of language into a number of functional-specific registers cannot be considered studied. According to Komarova, under the "functional-stylistic heterogeneity of speech register" it can be understood the difference in the proportions in which elements of different language functions used in the texts that make up each individual case. This heterogeneity is expressed in the growth of idiomatic texts on the same topic, a complication of linguistic organization of texts, in the elimination of lexical restrictions, in expanding the semantics of words, the appearance of expressive elements (Komarova).

\section{Method and Methodology}

To solve the problems was chosen a comprehensive approach to the study of the material: a method of contextual analysis, the method of entire philological analysis, descriptive and analytical method. 
Methodological basis of the study served as a general theory of functional styles and their related linguistic research presented in the foreign literature.

\section{Language Used for Specific Purposes}

Western researchers also made an enormous contribution to the study of functional-stylistic varieties of political, professional-oriented and commercial texts, operating under the name of a generalized language for specific purposes (LSP). The history of the formation and development of language for special purposes are carried out in the post-war period.'The concept of language for specific purposes appeared in the 1960s, as a result of scientific, technical and economic revolutions that require English language proficiency within a specific scientific and professional activity". However, the sectoral focus of language learning, albeit unconsciously, existed before. Researches show that there are five stages in the development of language for specific purposes: register analysis (Strevens, West, \& others); discourse analysis (Allen, Candlin, \& Widdowson); target situation analysis (Munby); skills and strategies (Grellet); learning-centered approach (Hutchinson).

However, we can speak about the appearance of the sixth stage of language development for specific purposes -learner-oriented approach - an approach that focuses on the student. A distinctive feature of this approach lies in the fact that the main focus is on the learner and his needs and interests. In the same context, in recent years teachers do not speak about the process of teaching, but the learning process, which involves primarily the efforts and abilities of the learner. The last four stages of language for special purposes indicate a departure from a linguistic analysis and passion for language teaching methodology. Language for academic purposes (EAP / English for Academic Purposes), released from the language for special purposes due to its functional-stylistic variety, divided into language for general academic purposes (EGAP / English for General Academic Purposes), and language for specific academic purposes (ESAP / English for Specific Academic Purposes). The last one is engaged in clarifying the principles of logical organization of political texts, establishment of their identity and structural differences, identifying their lexical, grammatical and stylistic features in various fields of political knowledge (Minyar Belorucheva). The language expert in the field of "International Relations" (EIRS / English for International Relations Students) is a component of language for special scientific purposes and, accordingly, his research includes analysis of language structure, the study of lexical and phraseological composition, grammar and style.

The study of language for specific purposes (LSP), which currently represents a symbiosis of philology and methods of teaching English language, is extremely urgent. This is due to the fact that the purpose of this research is to solve the serious contradictions between the traditional linguistic research and current practice of language teaching profession in high school. Practice of teaching language for special purposes is currently lagging behind the achievements of a theoretical nature. Considering language teaching as professional spheres of a new stage in the teaching of foreign languages, requiring special training for teachers and specialized textbooks, we must admit that teaching languages for specific purposes does not always correspond to the requirements of professional activities, to specialists of different professions and professionals in the field of "International Relations" in particular. "Methods of language for specific purposes are a kind of functional approach to language, involving stratification of its units depending on the scope of use. This approach connects linguistic theory and practice most successfully. The need for effective language learning with a view to the development of large volumes of text compels teachers not only completely change the nature of teaching materials, and in some cases, to quickly change the learning objectives depending on the skills required in the work of a specialist “

\section{Some Notes about Political Texts on International Relations}

The concept of "texts on International Relations" is carried out in functional stylistics. The texts of international relations may have different thematic focus within the perspective of international relations, as well as characterized by terminological heterogeneity. However, you can make the assumption that unifying diverse material can be recognized by their functional orientation that is the task serve as a means of communication, where the choice of the term or non-term expression can affect the outcome of international contacts. Scientific text as a means of clarifying the concepts in the field of "International Relations" provides an adequate understanding of the conditions and thus successful communication with international contacts.

Thus, according to the current definition, international relations - a set of economic, political, ideological, legal, diplomatic, military and cultural ties and relations between states and systems of states between the basic classes, social, economic and political forces, organizations and movements operating in the world stage. Accordingly, under the text on International Relations refers to texts which reflect all kinds of relations between states: economic, political, legal and cultural. Texts are divided into primary and secondary. 
The primary texts are texts of treaties, diplomatic documentation states - the documents, bearing the character of a purely intra-house, by which the written official relations between states and expressed the government's position on international issues. In the process of reading these texts provide a picture of the state's position on major international issues during their appearance. These documents are confidential and are not always made public. Of course, a large proportion of diplomatic documents concerning important issues of international life, is published, and it is judged that aspires to the State in international affairs.

Secondary texts are texts of articles and monographs, authors carry out an analysis of primary documents and theoretical understanding of the events taking place in the international arena. Foreign political issues in the processes taking place in international relations, affect the content, form, language aforesaid texts, giving them features that distinguish them from other kinds of political texts and releasing them in a separate register - "the language associated with the specific context of a particular field of knowledge or the scope of the use of" (Polyakov, p. 24).

The object of this study was secondary texts, namely the texts of monographs, the problem of the study which will remain relevant as long as countries around the world are working towards the preservation and development of international relations. Any educated person understands the role of international relations in our troubled world, and the fact that every word spoken or written with malicious intent, not giving value for this content and different linguistic subtleties of language, might lead to international conflicts and disasters. Unfortunately, history has many examples to prove it: the wrong expression of ideas by experts in the field of "International Relations", mistranslation - all of which can be fatal. Accordingly, the accuracy of the choice of linguistic resources in order to ensure a clear understanding of the non-conflict is a direct challenge not only to the specialist directly, but also a teacher, forming skills of future specialists.

International relations are science and public policy at the same time. In an effort to avoid conflicts in the international arena, government officials, ambassadors, diplomats created a multi-level language of international relations. On how well the ambassadors owned the language of international relations depended on the number of concessions that could be provided by the state. On how inaccurate a politician in his statements could depend on the prestige and importance of the state. Ambassadors, ministers have always been a person of the state, and how that person looks and how perfectly he mastered the language of international relations depends on the status of the entire nation. In the history of the diplomats there are cases where the spokesman tried to exasperate the opponent, making attempts to provoke a rude, thoughtless attack in order to use it against his country. To achieve this goal diplomat resorts to comparison, for example, as was the case in history, written agreements with the "scrap of paper" that was dismissive assessment of international commitments. This form of communication increased the likelihood of the conflict in the crisis, out of which the participants sought by military confrontation.

\section{Lexical Analysis of Political Texts on International Relations}

Textual political speech contributed to the development of a systematic approach to the study of lexicology functioning in political texts. As a result of textual analysis, it was found that the vocabulary of political texts has a heterogeneous composition. The most common layer is the general lexica-political area. As already mentioned, at the initial stage of its development textual analysis more attention was paid on a single word. Then the researches went on syntagmatics way, the science of the linear juxtaposition of minimal bilateral language units (Ter-Minasova).

The basic theoretical premise of this research is the provision set out in the course of the research, which share a common problem of differentiation of functional styles in terms of the characteristics of their syntagmatic, i.e., linear juxtaposition of linguistic units in speech. According to Ter-Minasova marginal unit of speech at the level of super-phrasal unity and further-global text are not individual words and their complex functional equivalents-phrases. In political texts lexical phraseological units were isolated, due to which there is an association of scientific statements. Many lexical predicative derivations regularly repeated in political texts, with non-terminological nature by which formalized a political text became known as "marginal syntagmatic sequences."

\subsection{Political Lexicon in the Political Texts on International Relations}

More recently, the study of the researches of political style was limited to the study of terminology in various fields of science. Currently, in the center of philological analysis stands non-terminological unit. It is important to note the achievement of textual political speech, namely the division of terminology itself different from the science of words that serve to express political concepts. The investigation of non-terminological vocabulary due to its quantitative predominates in the texts as compared with the terms. The study of general lexica-political 
items in the text, namely in political texts on International Relations allowed us to obtain a real picture of their operation.

When reviewing the list of lexical studies of political texts, we are witnessing their division into general political and special-political.

\subsection{Marginal Special Political Syntagmatic Sequences}

Marginal special political syntagmatic sequences function in political texts to reflect the specifics of a particular field of knowledge (in this case the field of "International Relations") and produced by the interaction of general political vocabulary layer with the terms of functioning in the field of "International Relations". These include marginal special political syntagmatic sequences used to recreate the picture of the past, explanation of facts, their evaluation and commenting, linking the available facts, comparing one with another fact, the establishment of a causal link, highlight the characteristics, as well as summarizing the outcome. (The state level of analysis consists of...; The global level of analysis refers to...; Before we attempt to unify the theory of general political types let us...; No systematic account of political ideas can omit a discussion...; The concept of political authority was analyzed in terms of...; Once we begin the political analysis in terms of preference we...; The comparative study of foreign policy suggests...; World-system theory raises questions about...; Our key hypothesis about the political type...).

\subsection{Marginal General Political Syntagmatic Sequences}

Marginal general political syntagmatic sequences are a universal unit of language with which a political statement in any field of knowledge formed, as each such statement contains categories such as the definition of the problem, the determination of goals and objectives, the transfer of knowledge. Marginal general political syntagmatic sequences reproduced in political texts on international relations as a sustainable means of linguistic expression of political thought. They are also interdisciplinary, as they arose from general political juxtaposition of words and are classified with reference to the general political key words.

In political texts on international relations marginal general political syntagmatic sequences are used in the following cases: in the formulation of research problems (The core of the problem is ...), determination its goals and objectives (What we are aiming at is ...), explanation of existing theories and points of view (The view that has been widely held in recent years ...), presentation the author's own concept (It is more important to consider the result rather than the cause of ...), the indication of the used sources (The work covers ...), summation(These facts give rise to important conclusions ...), and marginal special political syntagmatic sequences, reflecting the characteristics of political text on International Relations (It has been the practice in traditional political theorizing to ...).

The study of marginal general political syntagmatic sequences helped to understand the internal laws of the construction of a political text, as well as to draw a parallel between the logic of political thinking and units, it materializes. The specifics of activities of marginal general political syntagmatic sequencesin the political text is their uneven distribution in different parts of the structural and compositional political texts on international relations. For example, in the opening and closing parts of the politicaltext on International Relations, which define the goals and objectives and, accordingly, are summed up, the percentage of general political vocabulary increases compared with the main part of the political text on International Relations.

An analysis of the introduction of political texts on international relations has been allocated marginal general political syntagmatic sequences - "vision and perspective", which are used in the analysis and organization of political knowledge. The object of this essay...; But my object is not to refute...; We will consider first...; The book is not intended to be....; The book is meant to be...; I here attempt to qualify the themes set forth in the article and to develop many ideas and cover many topics...; The distant origins of the present volume lie in...; The present book is not a restatement of....; While the book is informed by recent world events, its subject returns to....; The answer I arrive at is...; This volume presents... We attempt to unify..., The book centers around... .

The second thematic group includes marginal syntagmatic sequences, reflecting the process of "knowledge acquisition", made up of the operations, such as monitoring, prediction and opening. For the revealing of the content of international relations specialists in "International Relations" has resorted to the use of logical means: to analysis, synthesis and conclusion. The acquisition of theoretical knowledge in the field of international relations is the result of the transformation of empirical data by logical means. Within this thematic group the following marginal syntagmatic sequences function: It may be observed...; This explained much of what followed...; Such interpretations cannot really explain, ..; It is not sufficient to account for...; This was later explained... 
In order to convince the reader that his version of the event-interpretation is the most appropriate, as well as to support their arguments in the framework of the thematic group "knowledge transfer", a specialist in the field of "International Relations" provides examples and illustrations, which are introduced with the following marginal syntagmatic sequences: The examples illustrate the...; To demonstrate it is essential to....

For the introduction of tables and figures such marginal syntagmatic sequences are used: As can be seen from the table...; Here are the figures for...; The best illustration of...is...; There is no better example of...

Structural organization of political text on international relations is characterized by logical harmony and consistency of presentation. This is reflected in the marginal general political syntagmatic sequences consisting of "meaningful, logical and compositional aspects of speech" and expressing "connection elements of the content and presentation logic." These are the marginal syntagmatic sequences which are one of the means to facilitate the transfer of information. They stimulate the reader's attention and indicate the order of information:

the beginning of the informing process: Our first effort to establish the basis...; The first point to be made is...; It is a useful starting point...; We may commence with ...;

continuation of the informing process: There is a further problem...; In this connection a question is bound to arise...; We shall proceed to....;

expression connection with the following statement: It will be briefly considered in the chapters on...; The book turns to a parallel account of the process in part...;

expression connection with the preceding statement: As we have indicated /noted earlier / in our earlier discussion; As I have already noted / stated / suggested;

making additions: To elucidate the theory of justice...; It is not to be forgotten...; It should be added that...; specification, clarification of the expressed thoughts: It is at this point that we can assume...; In other words...;

indication of the conclusion, summarizing the findings: It is therefore not surprising...; It is impossible to complete our present discussion...; What emerges from all of these processes...; The question of the end of history amounts to...; The final axis of interaction...; This leads to...; We must conclude...

Marginal syntagmatic sequences are used in the description of the various classifications constitute thematic group "systematization and organization of material":It is convenient to classify...; We can group it into broad types...; Classification of the wide range of this material has provided...; It falls into traditional categories...; The accumulation of new data shows that...

Thus, the material research showed that a significant amount of marginal stereotypical syntagmatic sequences, that's "semantic core" which are general political lexical units are used in political texts on international Relations.

\section{Conclusion}

Logical thinking of authors of political texts on international relations involves the combination of comprehension of facts, events, processes taking place in international relations, with the need to present them properly to the reader. Its mission is not only event registration, but their analysis. In order to have an impact on the reader to change its information field, an expert in the field of "International relations" can draw analogies and join never touch in time of civilization, as well as make predictions.

The study of political texts on International Relations led to the following conclusions:

The language of international relations and the history of the formation of international relations as a science are interrelated and interdependent. Comprehension of the unique language ofthe specialist in "International Relations" is achieved through its lexical level in conjunction with the evolution of international relations as a system. Lexical composition changes along with the social and political transformations. General lexico-political layer is its main area. The basis for the construction of political texts on international relations is marginal syntagmatic sequences - units of political speech, which are divided into general political and special political.

\section{References}

Allen, J. P. B. (1974). Corder S.P.G. Techniques in Applied Linguistics. London: New York.

Candlin, C. N. (1998). Researching academic literacies. Sydney, NSW: National Centre for English Language Teaching and Research University, Macquarie.

Close, R. A. (1966). The English We Use for Science. London.

Grellet, F. (1983). Developing Reading Skills. Cambridge, New York: Cambridge University Press. 
Hutchinson, T., \& Waters, A. (1999). English for Specific Purposes. Cambridge: Cambridge University Press.

Komarova, A. I. (1996). Language for specific purposes (LSP).

Polyakov, O. Q. (2003). English for specific purposes.

Strevens, P. (1980).Teaching English as an International Language: From Practice to Principle. London: Pergamon Press.

West, M. A. (1953). General Service List of English Words. London; New York: Longmans, Green.

Widdowson, H. G. (1965). Exploration in Applied Linguistics. Oxford: Oxford University Press.

\section{Copyrights}

Copyright for this article is retained by the author(s), with first publication rights granted to the journal.

This is an open-access article distributed under the terms and conditions of the Creative Commons Attribution license (http://creativecommons.org/licenses/by/3.0/). 